\title{
Barcode DNA Anthurium Gelombang Cinta (Anthurium plowmanii) berdasarkan gen $r b c L$ dan matK \\ (The DNA Barcode of Anthurium Wave of Love (Anthurium plowmanit) based on $r b c L$ and matK Genes)
}

\author{
Beivy J. Kolondam ${ }^{1)^{*}}$, Edy Lengkong ${ }^{2)}$, J. Polii-Mandang ${ }^{2)}$, \\ Semuel Runtunuwu') Arthur Pinaria ${ }^{2)}$ \\ 1) Jurusan Biologi Fakultas MIPA Universitas Sam Ratulangi Manado \\ 2) Jurusan Agroekoteknologi Fakultas Pertanian Universitas Sam Ratulangi Manado \\ *Email korespondensi: beivy_jk@yahoo.com
}

Diterima 3 Januari 2013, diterima untuk dipublikasikan 30 Januari 2013

\begin{abstract}
Abstrak
Metode standar untuk identifikasi spesies tumbuhan melalui barcode DNA telah direkomendasikan untuk menggunakan dua gen plastida yaitu rbcL dan matK. Tujuan penelitian ini yaitu untuk menentukan tingkat kemiripan sekuens barcode DNA tanaman Anthurium Gelombang Cinta (Anthurium plowmanii) dibandingkan spesies kerabatnya yang sudah terdata dalam BOLD Systems dan untuk merekomendasi penggunaan barcode DNA yang bisa diandalkan dalam mengidentifikasi spesies ini. Teknik Polymerase Chain Reaction (PCR) digunakan dalam perbanyakan sekuens fragmen gen rbcL dan gen matK oleh primer universal yang tersedia. Hasil penelitian menyimpulkan bahwa sampel tanaman A. plowmanii menghasilkan sekuens barcode rbcL yang mirip 100\% (identik) dengan spesies $A$. cubense. Ini berarti barcode DNA rbcL tidak dapat digunakan untuk identifikasi tingkat spesies. Sekuens barcode matK sampel menunjukkan kemiripan 99,1\% dengan $A$. ravenii yang berbeda dalam morfologi daun. Sekuens matK sampel bersifat unik diantara anggota-anggota genus Anthurium sehingga direkomendasikam penggunaannya untuk identifikasi sampai tingkat spesies.

Kata Kunci: barcode, rbcL, matK, Anthurium plowmanii
\end{abstract}

\begin{abstract}
Standard method for plant species identification through DNA barcode has been recommended to use two plastids genes; the rbcL and matK. The aims of this research were to determine similarities in DNA barcode sequences of Anthurium Wave of Love (Anthurium plowmanii) with its close relatives that listed in BOLD Systems and to recommend the reliable DNA barcode for identification of this species. Polymerase Chain Reaction was employed to amplify rbcL and matK genes fragments using available universal primers. The result showed that A. plowmanii sample was $100 \%$ similar to A. cubense. For that reason, the rbcL gene is not a reliable for species identification. Sequence of matK barcode showed $99.1 \%$ in similarity with $A$. ravenii which has different leaf shape. The matK sequence of sample was unique among all listed Anthurium members, therefore, this barcode are recommended for plant identification to the species level.

Keywords: barcode, rbcL, matK, Anthurium plowmanii
\end{abstract}




\section{PENDAHULUAN}

Perkembangan metode identifikasi spesies telah dimulai dari proses identifikasi secara morfologi sampai pada identifikasi molekuler berdasarkan potongan DNA pendek yang disebut "barcode DNA" (Hebert et al. 2003). Barcode DNA memiliki fungsi-fungsi aplikatif misalnya untuk survei ekologi (Dick dan Kress 2009), identifikasi takson-takson kriptik (Lahaye et al. 2008), dan konfirmasi sampel-sampel tanaman obat (Xue dan Li 2011). The Consortium for the Barcode of Life (CBOL) merekomendasikan dua gen plastida yaitu $r b c L$ dan matK sebagai barcode standar untuk identifikasi spesies tumbuhan (Hollingsworth et al. 2009).

Indonesia merupakan negara megabiodiversitas. Pendataan terhadap keragaman jenis tumbuhan di indonesia harus terus dilakukan untuk mengimbangi laju hilangnya keragaman. Salah satu tanaman hias yang pernah populer di Indonesia adalah Anthurium Gelombang Cinta atau Anthurium Wave of Love (Anthurium plowmanii). Istilah "Gelombang Cinta" diberikan karena bentuk daunnya yang bergelombang (Pulungan dan Wiendi 2010). Genus Anthurium merupakan salah satu anggota dari famili Araceae. Mattjik (2010) menjelaskan bahwa Anthurium memiliki daya tarik dan nilai ekonomis karena daunnya yang beragam dalam bentuk, ukuran, maupun warna. Anthurium digunakan sebagai tanaman hias ruangan di perumahan, perkantoran, tempat perbelanjaan, rumah sakit, hotel, maupun di bandar udara.

Dalam beberapa topik penelitian multidisiplin, barcode DNA adalah salah satu instrumen yang perlu disokong oleh ketersediaan database untuk identifikasi. Berdasarkan penelusuran dalam BOLD (Barcode of Life Database)
Systems yang terhubung dengan database sekuens dari beberapa negara, data sekuens DNA barcode standar ( $r b c L$ dan matK) banyak spesies belum tersedia atau belum lengkap untuk kedua gen barcode. Penelitian ini bertujuan untuk menentukan tingkat kemiripan sekuens DNA barcode A. plowmanii dengan spesies kerabatnya yang sudah terdata dalam BOLD Systems dan untuk merekomendasi penggunaan barcode DNA yang bisa diandalkan dalam mengidentifikasi spesies ini.

\section{METODE}

\section{Ekstraksi DNA Total Tanaman}

DNA total tanaman yang mencakup materi genetik inti, mitokondria, dan kloroplas (plastida), diekstrak dari potongan kecil lembaran daun satu tanaman $A$. plowmanii menggunakan Multisource Genomic DNA Miniprep Kit (Axygen) sesuai petunjuk manual. Modifikasi dilakukan untuk memaksimalkan ekstraksi DNA kloroplas yaitu dengan meningkatkan waktu lisis sel dari 30 menit menjadi satu jam dalam suhu $60^{\circ} \mathrm{C}$

\section{Polymerase Chain Reaction(PCR)}

Reaksi PCR dalam penelitian ini menggunakan 5X Ready-to-Load Master Mix (Solis Biodyne). Dalam setiap reaksi $50 \mu \mathrm{l}$ memiliki 1.25 Unit Taq DNA polimerase, $0,2 \mathrm{mM}$ masing-masing dNTPs, $1,5 \mathrm{mM}$ $\mathrm{MgCl}_{2}, \quad 0,2 \mathrm{mM}$ masing-masing primer, dan kira-kira 0,6 $\mu \mathrm{g}$ DNA total sampel. Untuk primer digunakan primer universal yaitu rbcLaF (5'-ATG TCA CCA CAA ACA GAG ACT AAA GC-3') dan rbcLaR (5'-GTA AAA TCA AGT CCA CCR CG-3') untuk amplifikasi gen $r b c L$ (Kress dan Erickson 2007) serta untuk gen matK digunakan matK-3F 
(5'-CGT ACA GTA CTT TTG TGT TTA CGA G-3') dan matK-1R (5'ACC CAG TCC ATC TGG AAA TCT TGG TTC-3').

Pengaturan suhu thermocycler dimulai dengan denaturasi awal pada $95^{\circ} \mathrm{C}$ selama 2 menit kemudian dilanjutkan 35 siklus [95ㅇ 30 detik, $\mathrm{X}^{\circ} \mathrm{C} 30$ detik, dan $72^{\circ} \mathrm{C} 1$ menit]. Suhu $X$ untuk perlekatan primer (annealing) yang disarankan Stoeckle et al. (2011) adalah 55은 untuk rbcL dan $52^{\circ} \mathrm{C}$ untuk matK. DNA hasil PCR divisualisasi menggunakan elektroforesis gel agarosa $1 \%$ dan sisanya dikirim untuk sekuensing ke penyedia jasa sekuensing bersama primer. Proses sekuensing dilakukan sebanyak dua kali dengan arah yang berbeda (forward dan reverse) sesuai primer yang ada.

\section{Analisis Data}

Kromatogram yang diperoleh dari hasil sekuensing disunting menggunakan software Geneious v5.6 (Drummond et al. 2012). Bagian awal DNA dihapus kira-kira 30 bp dan pembacaan nukleotida yang keliru diperbaiki berdasarkan tingkat keakuratan terbaca. Terhadap hasil sekuensing menggunakan primer reverse dilakukan proses reverse and complement kemudian dipadukan dengan hasil sekuensing primer forward menggunakan MUSCLE (Multiple Sequence Comparison by Log-Expectation) oleh Edgar (2004).

Keakuratan amplifikasi gen target diuji dengan memprediksi urutan asam amino berdasarkan masing-masing sekuens $r b c L$ dan matK. Hal ini bertujuan untuk melihat adanya kodon stop (UAA, UAG atau UGA) di tengah sekuens gen-gen aktif tersebut sehingga diketahui pasti bahwa yang teramplifikasi bukan gen semu (pseudogene). Potongan gen rbcL dan matK diidentifikasi lewat BOLD (Barcode of Life Database)
Penelusuran sekuens barcode $r b c L$ sampel tanaman Gelombang Cinta pada database BOLD Systems ternyata menghasilkan kemiripan $100 \%$ (identik) dengan spesies Anthurium cubense. Perbandingan A. plowmanii secara morfologi dan A. cubense yang dilakukan oleh pakar yang sama yaitu Dr. Thomas Croat (Lucas, 2008; Lucas, 2009). Pakar ini menggambarkan bahwa kedua spesies berbagi kemiripan ciri morfologi sehingga dikategorikan berkerabat dekat (satu genus), yaitu adanya ciri tepi daun bergelombang yang dimiliki keduanya.Systems (www.boldsystems.org)

(Ratnasingham dan Hebert 2007).

\section{HASIL DAN PEMBAHASAN}

Sekuensing produk PCR dari kedua gen menghasilkan kromatogram yang berkualitas tinggi. Nilai $\mathrm{HQ \%}$ kromatogram yang terbaca dalam Geneious v5.6 adalah $>86.8 \%$ untuk rbcL dan $>94.0 \%$ untuk matK (data tidak ditampilkan). Panjang pita DNA teramplifikasi yaitu 599 bp untuk sekuens $r b c L$ dan 889 bp untuk sekuens matK. Gambar 1 dan Gambar 2 menunjukkan bahwa tidak ada kodon stop yang terbentuk di tengah-tengah sekuens. $\mathrm{Hal}$ ini berarti hasil amplifikasi DNA yang dilakukan bersifat valid mengingat kedua gen tersebut adalah fragmen yang termasuk dalam bingkai bacaan terbuka (open reading frame) dari enzim-enzim fotosintesis. Gen rbcL menggunakan frame 1 (pembacaan dimulai asam dari amino pertama) sedangkan gen matK menggunakan frame 3 (pembacaan dimulai dari asam amino ketiga). 


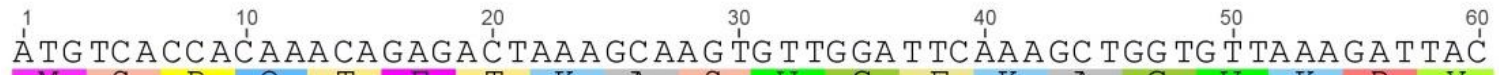

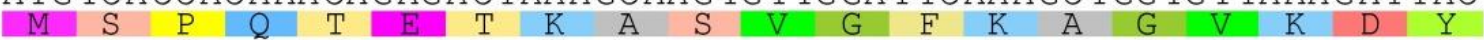
$\begin{array}{lllll}70 & 80 & 90 & 100 & 110\end{array}$

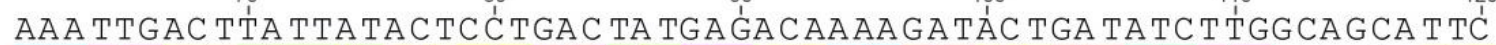

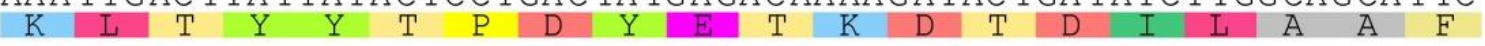
$1300150 \quad 150 \quad 160 \quad 170 \quad 180$

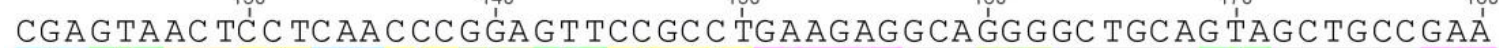

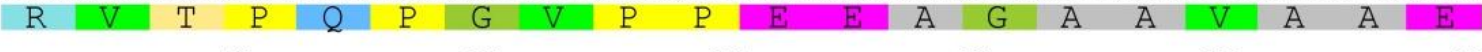
TC T TC TAC TGG TACA TGGA $\begin{array}{llllllllllllllllllll}S & S & T & G & T & W & T & T & V & W & T & D & G & L & T & S & L & D & R & Y\end{array}$ $250 \quad 260 \quad 270 \quad 280 \quad 300$ AAAGGACGA T'GCTACCACA TTGAAGCCG T TG T TGGG GAGGAAAA TCAATÁ TA TTGCT TA T'

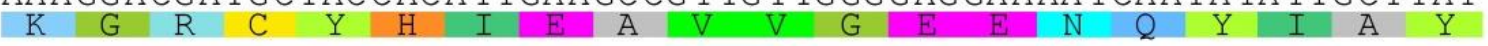

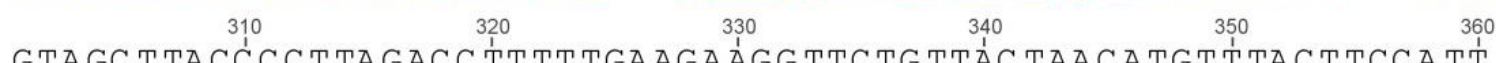

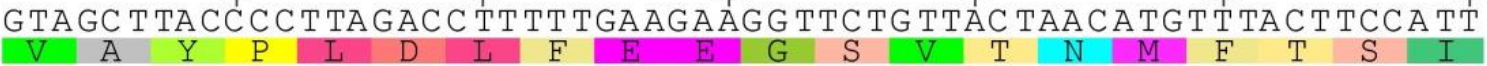

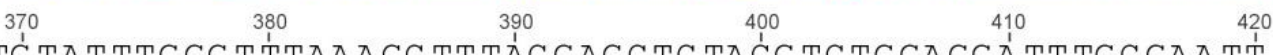

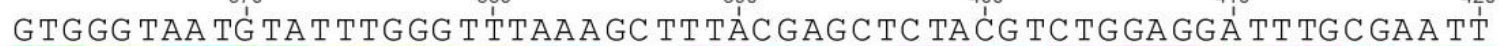
$\begin{array}{lllllllllllllllllllll}V & G & N & V & F & G & F & K & A & L & R & A & L & R & L & E & D & L & R & I\end{array}$

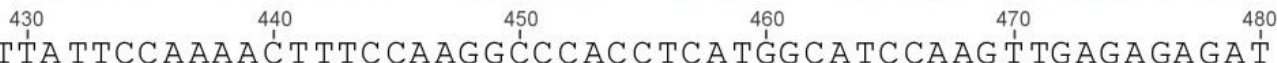

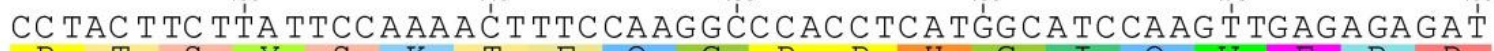

\begin{tabular}{llllllllllllllllllllll}
$P$ & $T$ & $S$ & $Y$ & $S$ & $K$ & $T$ & $F$ & $Q$ & $G$ & $P$ & $P$ & $H$ & $G$ & $I$ & $Q$ & $V$ & $E$ & $R$ & $D$ \\
\hline
\end{tabular}

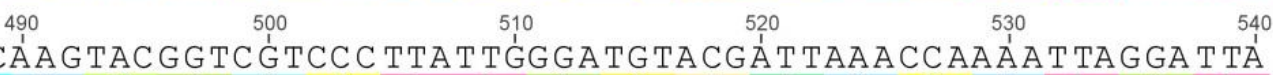

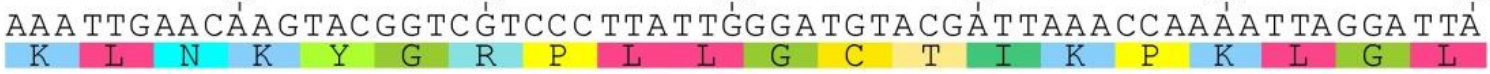

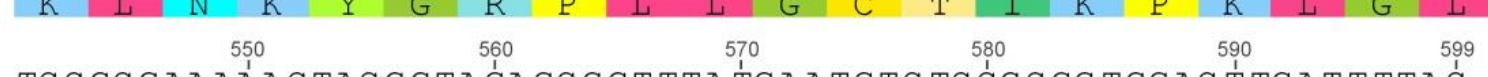

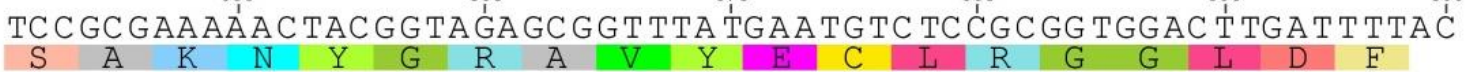

Gambar 1. Sekuens DNA barcode rbcL dan Asam Amino Tanaman Gelombang Cinta (Anthurium plowmanii) 


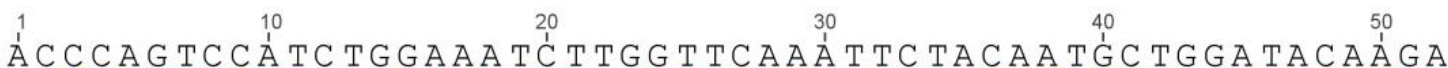

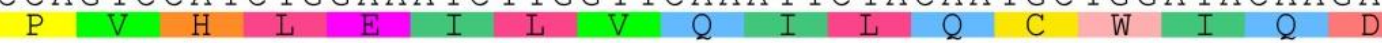

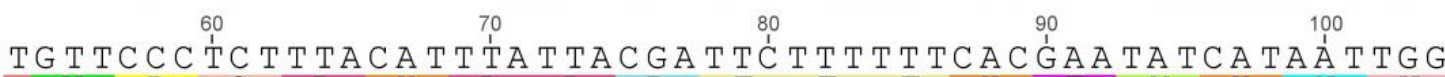

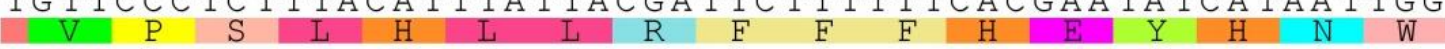

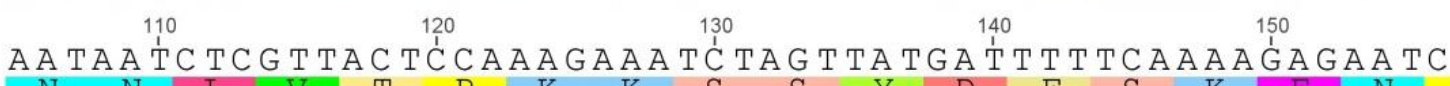

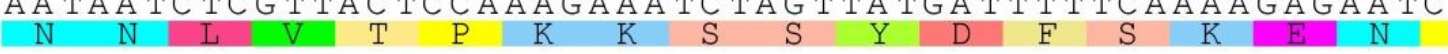
$16001800190 \quad 190 \quad 200$

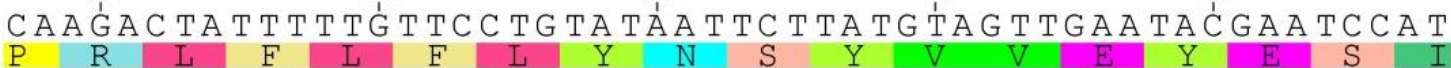
$210 \quad 220 \quad 230 \quad 240 \quad 250 \quad 260$

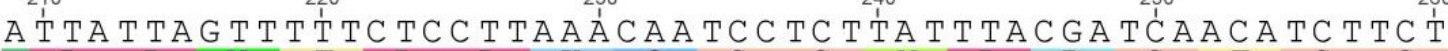
$\begin{array}{lllllllllllll}L & L & F & F & L & L & K & Q & S & S & Y & L & S\end{array}$

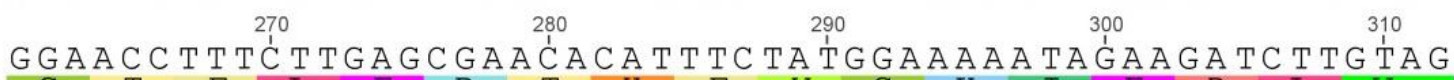

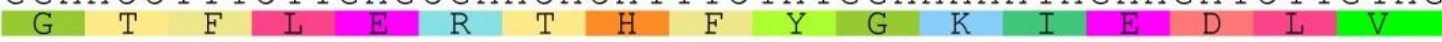

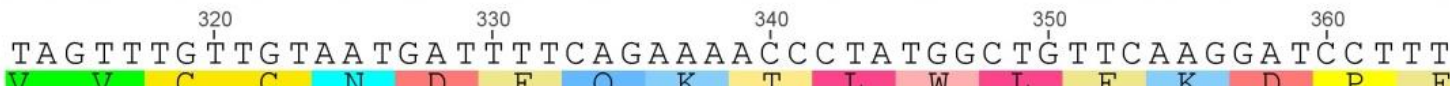

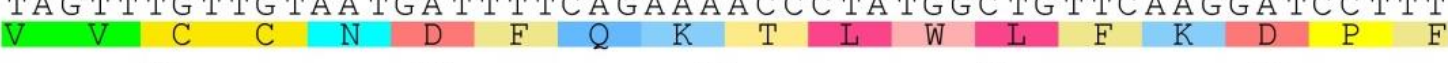
$370 \quad 380 \quad 390 \quad 400 \quad 410$

CATGCÀTTATGTTAGÄTATCAAGGA ȦATCGATTC TAGCTTCAAA ṪGGACT

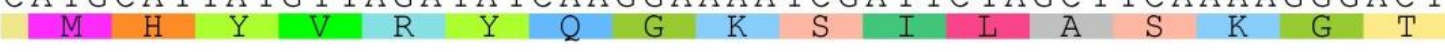
$420 \quad 430 \quad 440 \quad 450 \quad 460$

CATC T TT TA TGA $\begin{array}{lllllllllllllllll}H & L & L & M & N & K & W & K & S & Y & F & V & N & F & W & Q & C\end{array}$

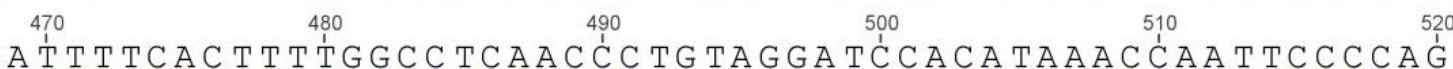

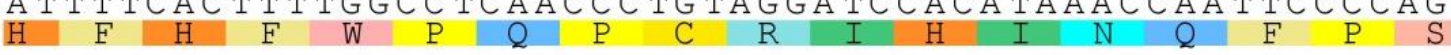
$530 \quad 540 \quad 550 \quad 560 \quad 570$

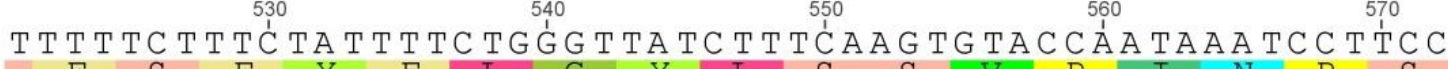

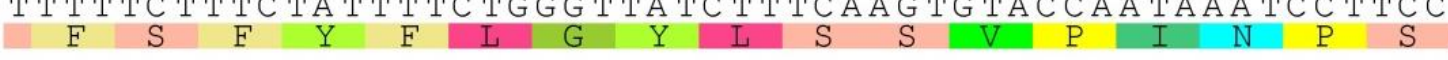
$580 \quad 590 \quad 600 \quad 610 \quad 620$ GCGGTAA

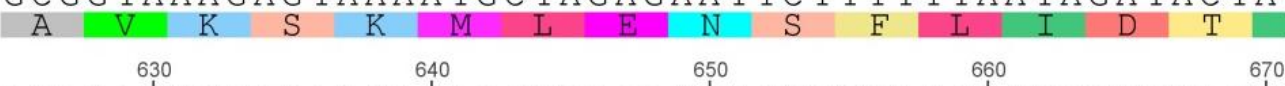

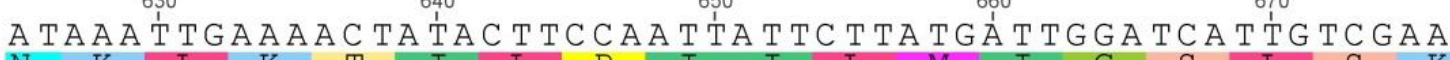

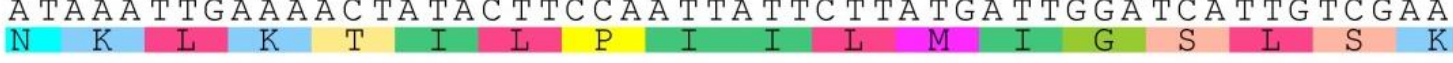
$6800 \quad 690 \quad 700 \quad 710 \quad 720$

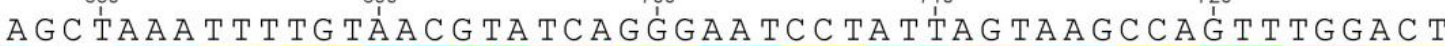

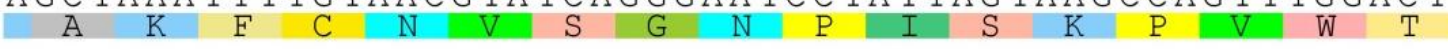
G

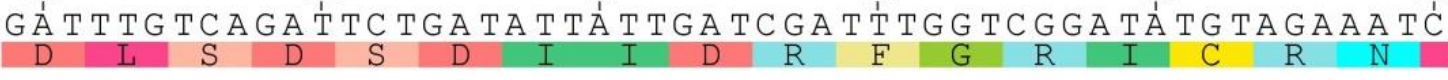
$790 \quad 800 \quad 810 \quad 820 \quad 830$

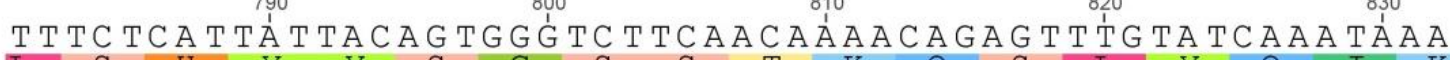

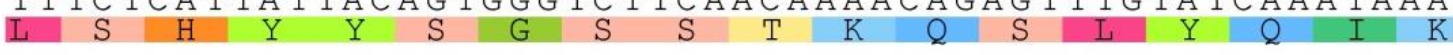
$840 \quad 850 \quad 860 \quad 870 \quad 880$

GTATATA C T TCGACTTTCATGTGCTAG ̈厶ACTTTGGCTCGTAAACACA

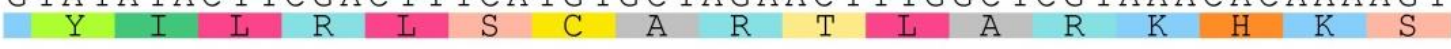
$\underset{\mathrm{T}}{\mathrm{ACT} T \mathrm{~T}^{\frac{1}{\mathrm{~A}}} \mathrm{CG}}$

Gambar 2. Sekuens DNA barcode matK dan Asam Amino Tanaman Gelombang Cinta (Anthurium plowmanii) 


\begin{tabular}{|c|c|c|c|c|c|c|c|c|c|}
\hline Processid & Phylum & Class & Order & Family & Genus & Species & Score & Similarity & $\begin{array}{c}\text { E- } \\
\text { Value }\end{array}$ \\
\hline $\begin{array}{c}\text { MHPAC943- } \\
11\end{array}$ & Magnoliophyta & Liliopsida & Alismatales & Araceae & Anthurium & cubense & 552 & 100 & 0 \\
\hline $\begin{array}{c}\text { MHPAC941- } \\
11\end{array}$ & Magnoliophyta & Liliopsida & Alismatales & Araceae & Anthurium & cubense & 552 & 100 & 0 \\
\hline $\begin{array}{c}\text { MHPAC942- } \\
11\end{array}$ & Magnoliophyta & Liliopsida & Alismatales & Araceae & Anthurium & cubense & 552 & 100 & 0 \\
\hline $\begin{array}{c}\text { CALAK714- } \\
10\end{array}$ & Magnoliophyta & Liliopsida & Alismatales & Araceae & Anthurium & gracile & 550 & 99.82 & 0 \\
\hline $\begin{array}{l}\text { MHPAA262- } \\
08\end{array}$ & Magnoliophyta & Liliopsida & Alismatales & Araceae & Anthurium & & 550 & 99.82 & 0 \\
\hline $\begin{array}{c}\text { MHPAD554- } \\
09\end{array}$ & Magnoliophyta & Liliopsida & Alismatales & Araceae & Anthurium & spectabile & 550 & 99.82 & 0 \\
\hline $\begin{array}{l}\text { MHPAC1615- } \\
11\end{array}$ & Magnoliophyta & Liliopsida & Alismatales & Araceae & Anthurium & ravenii & 548 & 99.64 & 0 \\
\hline $\begin{array}{c}\text { MHPAC1614- } \\
11\end{array}$ & Magnoliophyta & Liliopsida & Alismatales & Araceae & Anthurium & ravenii & 548 & 99.64 & 0 \\
\hline $\begin{array}{c}\text { MHPAF736- } \\
11\end{array}$ & Magnoliophyta & Liliopsida & Alismatales & Araceae & Anthurium & ravenii & 548 & 99.64 & 0 \\
\hline $\begin{array}{c}\text { MHPAF737- } \\
11\end{array}$ & Magnoliophyta & Liliopsida & Alismatales & Araceae & Anthurium & ravenii & 548 & 99.64 & 0 \\
\hline $\begin{array}{c}\text { CBVB1007- } \\
11\end{array}$ & Magnoliophyta & Liliopsida & Alismatales & Araceae & Anthurium & scherzerianum & 546 & 99.46 & 0 \\
\hline $\begin{array}{c}\text { MHPAD3162- } \\
10\end{array}$ & Magnoliophyta & Liliopsida & Alismatales & Araceae & Anthurium & ochranthum & 546 & 99.46 & 0 \\
\hline $\begin{array}{c}\text { MHPAD3399- } \\
10\end{array}$ & Magnoliophyta & Liliopsida & Alismatales & Araceae & Anthurium & ochranthum & 546 & 99.46 & 0 \\
\hline $\begin{array}{c}\text { MHPAD3398- } \\
10\end{array}$ & Magnoliophyta & Liliopsida & Alismatales & Araceae & Anthurium & ochranthum & 546 & 99.46 & 0 \\
\hline $\begin{array}{c}\text { MHPAF195- } \\
11\end{array}$ & Magnoliophyta & Liliopsida & Alismatales & Araceae & Anthurium & interruptum & 546 & 99.46 & 0 \\
\hline $\begin{array}{c}\text { MHPAF127- } \\
11\end{array}$ & Magnoliophyta & Liliopsida & Alismatales & Araceae & Anthurium & bakeri & 546 & 99.46 & 0 \\
\hline $\begin{array}{c}\text { MHPAF072- } \\
11\end{array}$ & Magnoliophyta & Liliopsida & Alismatales & Araceae & Anthurium & bakeri & 546 & 99.46 & 0 \\
\hline $\begin{array}{c}\text { MHPAD3156- } \\
10\end{array}$ & Magnoliophyta & Liliopsida & Alismatales & Araceae & Anthurium & scandens & 546 & 99.46 & 0 \\
\hline $\begin{array}{c}\text { MHPAD3155- } \\
10\end{array}$ & Magnoliophyta & Liliopsida & Alismatales & Araceae & Anthurium & scandens & 546 & 99.46 & 0 \\
\hline $\begin{array}{c}\text { MHPAD3396- } \\
10\end{array}$ & Magnoliophyta & Liliopsida & Alismatales & Araceae & Anthurium & ochranthum & 544 & 99.45 & 0 \\
\hline
\end{tabular}

Record: CALAK714-10, Indentified As: Anthurium gracile

Score: 550, E-Value: 0, Identity: 551//552 (100\%), Gaps:
Query AGTGTTGGATTCAAAGCTGGTGTTAAAGATTACAAATTGACTTATTATACTCCTGACTATGAGACAAAAGATACTGATATCTTGGCAGCA Sbjct $\begin{aligned} & \text { IIIIIIIIIIIIIIIIIIIIIIIIIIIIIIIIIIIIIIIIIIIIIIIIIIIIIIIIIIIIIIIIIIIIIIIIIIIIIIIIIIIIIIIIII } \\ & \text { Matched sequence is private and can't be displayed. }\end{aligned}$ $\begin{array}{ll}\text { Sbjet } & \text { Matched sequence is private and can't be displayed. } \\ \text { Query } & \text { TTCCGAGTAACTCCTCAACCCGGAGTTCCGCCTGAAGAGGCAGGGGCTGCAGTAGCTGCCGAATCTTCTACTGGTACATGGACAACTGTG }\end{array}$ Query TTCCGAGTAACTCCTCAACCCGGAGTTCCGCCTGAAGAGGCAGGGGCTGCAGTAGCTGCCGAATCTTCTACTGGTACATGGACAACTGTG $\begin{array}{ll}\text { Sbjct } & \text { Matched sequence is private and can't be displayed. } \\ \text { Query } & \text { TGGACTGATGGACTTACCAGTCTTGATCGTTACAAAGGACGATGCTACCACATTGAAGCCGTTGTTGGGGAGGAAAATCAATATATTGCT }\end{array}$ 111111111111111111111111111111111111111111111111111111111111111111111 Query TATGTAGCTTACCCTTAGACCTTTTTGAAGAAGGTTCTGTTACTAACATGTTTACTTCCATTGTGGGTAATGTATTTGGGTTTAAAGCT Sbjct IIIIIIIIIIIIIIIIIIIIIIIIIIIIIIIIIIIIIIIIIIIIIIIIIIIIIIIIIIIIIIIIIIIIIIIIIIIIIIIIIIII $\begin{array}{ll}\text { Sbjct } & \text { Matched sequence is private and can't be displayed. } \\ \text { Query } & \text { TTACGAGCTCTACGTCTGGAGGATTTGCGATTCCTACTTCTTATTCCAAAACTTTCCAAGGCCCACCTCATGGCATCCAAGTTGAGAGA }\end{array}$ Query TTACGAGCTCTACGTCTGGAGGATTTGCGAATTCCTACTTCTTATTCCAAAACTTTCCAAGGCCCACCTCATGGCATCCAAGTTGAGAGA Matched sequence is private and can't be displayed. 1111111111111111111111111111111111111111111111111111111111111111111111111111111111111111111 Matched sequence is private and can't be displayed. TATGAATGTCTC
M IIIIIIIIII
Matched sequence is private and can't be displayed.
Query
Sbjct

Record: MHPAD554-09, Indentified As: Anthurium spectabile

Score: 550, E-Value: 0, Identity: 551//552 (100\%), Gaps:

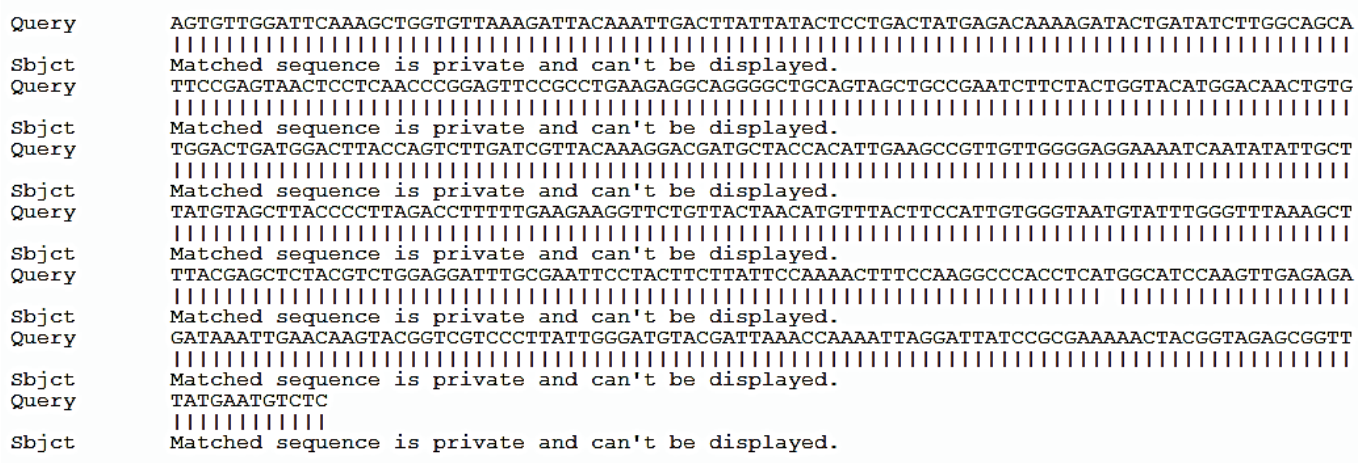

Gambar 3. Penelusuran BOLD Systems untuk Sekuens rbcL Tanaman Gelombang Cinta (Anthurium plowmanii) Tanggal 8 Agustus 2012 
Kolondam dkk., Barcode DNA .... 23

\begin{tabular}{|c|c|c|c|c|c|c|c|c|c|}
\hline Processid & Phylum & Class & Order & Family & Genus & Species & Score & Similarity & $\begin{array}{c}\text { E- } \\
\text { Value }\end{array}$ \\
\hline $\begin{array}{c}\text { CALAK675- } \\
10\end{array}$ & Magnoliophyta & Liliopsida & Alismatales & Araceae & Anthurium & schlechtendalii & 766 & 98.98 & 0 \\
\hline $\begin{array}{c}\text { CBVA1608- } \\
11\end{array}$ & Magnoliophyta & Liliopsida & Alismatales & Araceae & Anthurium & acaule & 761 & 97.51 & 0 \\
\hline $\begin{array}{l}\text { MHPAC1615- } \\
11\end{array}$ & Magnoliophyta & Liliopsida & Alismatales & Araceae & Anthurium & ravenii & 758 & 99.1 & 0 \\
\hline $\begin{array}{l}\text { MHPAA646- } \\
08\end{array}$ & Magnoliophyta & Liliopsida & Alismatales & Araceae & Anthurium & & 758 & 99.1 & 0 \\
\hline $\begin{array}{l}\text { MHPAA513- } \\
08\end{array}$ & Magnoliophyta & Liliopsida & Alismatales & Araceae & Anthurium & brenesii & 756 & 98.97 & 0 \\
\hline $\begin{array}{l}\text { MHPAD554- } \\
09\end{array}$ & Magnoliophyta & Liliopsida & Alismatales & Araceae & Anthurium & spectabile & 756 & 99.09 & 0 \\
\hline $\begin{array}{l}\text { MHPAF127- } \\
11\end{array}$ & Magnoliophyta & Liliopsida & Alismatales & Araceae & Anthurium & bakeri & 754 & 98.84 & 0 \\
\hline $\begin{array}{l}\text { MHPAF071- } \\
\quad 11\end{array}$ & Magnoliophyta & Liliopsida & Alismatales & Araceae & Anthurium & bakeri & 754 & 98.84 & 0 \\
\hline $\begin{array}{l}\text { MHPAF072- } \\
11\end{array}$ & Magnoliophyta & Liliopsida & Alismatales & Araceae & Anthurium & bakeri & 754 & 98.84 & 0 \\
\hline $\begin{array}{l}\text { MHPAF195- } \\
11\end{array}$ & Magnoliophyta & Liliopsida & Alismatales & Araceae & Anthurium & interruptum & 750 & 98.58 & 0 \\
\hline $\begin{array}{l}\text { MHPAA618- } \\
08\end{array}$ & Magnoliophyta & Liliopsida & Alismatales & Araceae & Anthurium & & 750 & 98.58 & 0 \\
\hline $\begin{array}{c}\text { CBVA1944- } \\
11\end{array}$ & Magnoliophyta & Liliopsida & Alismatales & Araceae & Schismatoglottis & multiflora & 743 & 94.42 & 0 \\
\hline $\begin{array}{c}\text { CBVA1953- } \\
11\end{array}$ & Magnoliophyta & Liliopsida & Alismatales & Araceae & Schismatoglottis & sp.SYW-2010a & 741 & 94.31 & 0 \\
\hline $\begin{array}{c}\text { CBVA } 1949- \\
11\end{array}$ & Magnoliophyta & Liliopsida & Alismatales & Araceae & Schismatoglottis & pyrrhias & 741 & 94.31 & 0 \\
\hline $\begin{array}{c}\text { CBVA } 1946- \\
11\end{array}$ & Magnoliophyta & Liliopsida & Alismatales & Araceae & Schismatoglottis & multinervia & 741 & 94.31 & 0 \\
\hline $\begin{array}{c}\text { CBVA1943- } \\
11\end{array}$ & Magnoliophyta & Liliopsida & Alismatales & Araceae & Schismatoglottis & multiflora & 741 & 94.31 & 0 \\
\hline $\begin{array}{c}\text { CBVA } 1942- \\
11\end{array}$ & Magnoliophyta & Liliopsida & Alismatales & Araceae & Schismatoglottis & multiflora & 741 & 94.31 & 0 \\
\hline $\begin{array}{l}\text { CBVA1940- } \\
11\end{array}$ & Magnoliophyta & Liliopsida & Alismatales & Araceae & Schismatoglottis & multiflora & 741 & 94.31 & 0 \\
\hline $\begin{array}{c}\text { CBVA1931- } \\
11\end{array}$ & Magnoliophyta & Liliopsida & Alismatales & Araceae & Schismatoglottis & jepomii & 741 & 94.31 & 0 \\
\hline $\begin{array}{c}\text { CBVA1924- } \\
11\end{array}$ & Magnoliophyta & Liliopsida & Alismatales & Araceae & Schismatoglottis & corneri & 741 & 94.31 & 0 \\
\hline
\end{tabular}

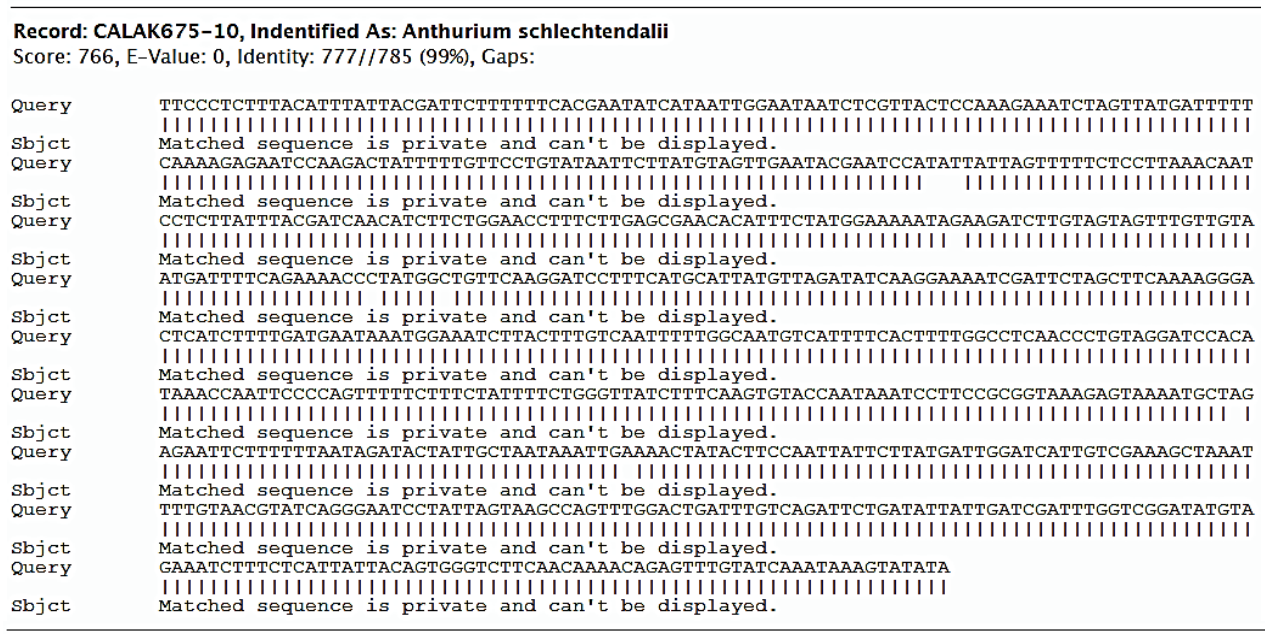

Record: MHPAC1615-11, Indentified As: Anthurium ravenii

Score: 758, E-Value: 0, Identity: 768//775 (99\%), Gaps:

Query CCCTCTTTACATTTATTACGATTCTTTTTTCACGAATATCATAATTGGAATAATCTCGTTACTCCAAAGAAATCTAGTTATGATTTTTCA

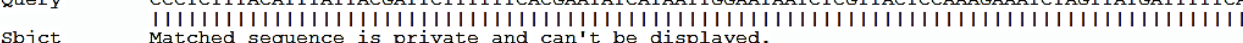

$\begin{array}{ll}\text { Sbjct } & \text { Matched sequence is private and can't be displayed. } \\ \text { Query } & \text { AAAGAGAATCCAAGACTATTTTTGTTCCTGTATAATTCTTATGTAGTTGAATACGAATCCATATTATTAGTTTTTCTCCTTAAACAATCC }\end{array}$

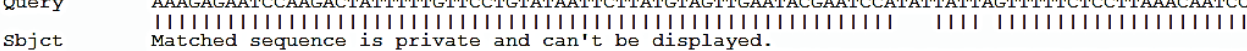

$\begin{array}{ll}\text { Sbjet } & \text { Matched sequence is private and can't be displayed. } \\ \text { Query } & \text { TCTTATTIACGATCAACATCTTCTGGAACCTTTCTTGAGCGAACACATTTCTATGGAAAAATAGAAGATCTTGTAGTAGTTTGTTGTAAT }\end{array}$

Query TCTTATTIACGATCAACATCTTCTGGAACCTTCTTGAGCGAACACATTTCTATGGAAAAATAGAAGATCTTGTAGTAGTTTGTTGTAAT

Sbjet Matched sequence is private and can't be displayed.

Sbjct $\begin{aligned} & \text { MATIIIIIIIIIIIIIIIIII IIIIIIIIIIIIIIIIIIIIIIIIIIIIIIIIIIIIIIIIIIIIIIIIIIIIIIIIIIIIIIIIIIII } \\ & \text { Matched sequence is private and can't be displayed. }\end{aligned}$

$\begin{array}{ll}\text { Sbjct } & \text { Matched sequence is private and can' } t \text { be displayed. } \\ \text { Query } & \text { CATCTTTTGATGAATAAATGGAATCTTACTTTGTCATTTTGGCAATGTCATTTCACTTTTGGCCTCAACCCTGTAGGATCCACATA }\end{array}$

Query CATCTTTTGATGAATAAATGGAAATCTTACTTTGTCAATTTTTGGCAATGTCATTTTCACTTTTGGCCTCAACCCTGTAGGATCCACATA

Sbjet Matched sequence is private and can't be displayed.

Query AACCAATTCCCAGTTTTCTTTCTATTTTCTGGGTTATCTTTCAAGTGTACCAATAAATCCTTCCGCGGTAAGAGTAAAATGCTAGAG

Sbjet Matched sequence is private and can' $t$ be displayed.

Query AATTCTTTTTTAATAGATACTATTGCTAATAAATTGAAACTATACTTCCAATTATTCTTATGATTGGATCATTGTCGAAAGCTAAATTT

$\begin{array}{ll}\text { Sbjct } & \text { Matched sequence is private and can't be displayed. } \\ \text { Query } & \text { TGTAACGTATCAGGGATCCTATTAGTAAGCAGTTGGACTGATTTGTAGATTCTGATATTATTGATCGATTTGGTCGGATATGTAGA }\end{array}$

$\begin{array}{ll}\text { QuerY } & \text { TGTAACGTATCAGGGATCCTATTAGTAAGCCAGTTTGGACTGATTTGTCAGATTCTGATATTATTGATCGATTTGGTCGGATATGTAGA } \\ \text { Sbjct } & \text { Matched sequence is private and can't be displayed. }\end{array}$

Query AATCTTTCTCATTATTACAGTGGGTCTTCAACAAAACAGAGTTTGTATCAAATAA

Sbjct
Matched sequence is private and can't be displayed.

Gambar 4. Penelusuran BOLD Systems untuk Sekuens matK Tanaman Gelombang Cinta (Anthurium plowmanii) Tanggal 8 Agustus 2012 
Mempertimbangkan sekuens rbcL spesies lain, tingkat kemiripan sampel tanaman Gelombang Cinta juga sangat tinggi dengan $A$. gracile dan $A$. spectabile yaitu $99,82 \%$ untuk keduanya. Perbandingan antara sekuens $r b c L$ kedua spesies ini juga menunjukkan kemiripan 100\% (identik) satu sama lain (Gambar 3). Kemungkinan yang terjadi adalah barcode rbcL memiliki kemampuan pembeda yang lemah. Kemungkinan lain yaitu studi-studi sebelumnya yang mengidentifikasi spesies sama dengan penamaan berbeda.

Perbandingan sekuens matK sampel dalam database menghasilkan kemiripan yang tinggi dengan sesama anggota genus Anthurium tetapi tidak ada yang identik (Gambar 4). Kemiripan tertinggi yaitu dengan $A$. ravenii $(99,1 \%)$ sedangkan skor tertinggi yaitu dengan $A$. schlechtendalii (766). Nilai skor ini diperoleh dari jumlah nukleotida yang tercakup dalam perbandingan.

Penelusuran kemiripan sekuens barcode matK dilakukan melalui pembandingan dengan $A$. plowmanii. Tumbuhan $A$. ravenii memiliki perbedaan yang signifikan (bentuk daun yang segitiga) apabila dibandingkan $A$. plowmanii (Croat 2012). Tumbuhan $A$. schlechtendalii memiliki bentuk daun yang mirip $A$. plowmanii, bahkan awalnya dianggap sebagai variasi dari spesies ini (Lucas 2006). Berdasarkan Gambar 4, tingkat kemiripan antara anggota genus Anthurium dalam BOLD termasuk tinggi yaitu $>98,58 \%$. Terdapat perbedaan besar dengan genus terdekat yang terdata yaitu Schismatoglottis $\quad(94,42 \%$ untuk Schismatoglottis multiflora). Dari analisis perbedaan morfologi dan sekuens barcode matK antara spesies-spesies ini menunjukkan adanya keunikan barcode yang bisa diandalkan untuk identifikasi $A$. plowmanii.

\section{Lemahnya}

kemampuan diskriminasi barcode rbcL telah ditunjukkan oleh beberapa publikasi sebelumnya (Hollingsworth et al. 2009; Hollingsworth et al. 2011). Walaupun kemampuan diskriminasi gen ini tidak lebih baik dari penanda lain, barcode rbcL memiliki tingkat keberhasilan amplifikasi yang tinggi untuk banyak spesies dan mudah disekuensing (Hollingsworth et al. 2011). Barcode rbcL dalam penelitian ini mampu membedakan sampel hanya sampai pada tingkat genus saja.

\section{KESIMPULAN}

Berdasarkan hasil dan pembahasan dapat disimpulkan bahwa sekuens barcode rbcL sampel tanaman $A$. plowmanii menghasilkan kemiripan $100 \%$ (identik) dengan spesies $A$. cubense sehingga barcode ini tidak dapat digunakan untuk identifikasi sampai pada tingkat spesies. Sekuens barcode matK sampel bersifat unik sehingga mampu digunakan untuk identifikasi sampai tingkat spesies.

\section{DAFTAR PUSTAKA}

Croat TB (2012) Anthurum ravenii Croat \& Baker. http://www. aroid.org/genera/anthurium/ca lomystrium/ravenii.php.

Diakses pada 9 Agustus 2012

Dick CW, Kress WJ (2009) Dissecting tropical plant diversity with forest plots and a molecular toolkit. Bioscience 59: 745-755

Drummond AJ, Ashton B, Buxton S, Cheung M, Cooper A, Duran C, Field M, Heled J, Kearse M, Markowitz S, Moir R, Stones-Havas S, Sturrock S, Thierer T, Wilson A (2012) Geneious v5.6. Biomatters. New Zealand 
Edgar RC (2004) MUSCLE: Multiple sequence alignment with high accuracy and high throughput. Nucleic Acid Res 32 (5): 1792-1797

Hebert PDN, Cywinska NA, Ball SL, de Waard JR (2003) Biological identifications through DNA barcodes. Proc Roy Soc B-Biol Sci 270: 313321

Hollingsworth PM, Graham SW, Little DP (2011) Choosing and using a plant DNA barcode. PloSONE (6): e19254

Hollingsworth PM, Forrest LL, Spouge JL, Hajibabaei M, Ratnasingham R (2009) A DNA barcode for land plants. Proc Natl Acad Sci USA 106: 12794-12797

Kress WJ, Erickson DL (2007) A twolocus global DNA barcode for land plants: the coding $\mathrm{rbcL}$ gene complements the noncoding trnH-psbA spacer region. PLOSONE 2 (6): e508

Lahaye R, Van der Bank M, Bogarin D, Warner J, Pupulin F, Gigot $\mathrm{G}$, Maurin $\mathrm{O}$, Duthoit $\mathrm{S}$, Barraclough TG, Savolainen V (2008) DNA barcoding the floras of biodiversity hotspots. Proc Nat Acad Sci 105(8): 2923-2928

Lucas S (2006) Anthurium schlechtendalii. http://www. exoticrainforest.com/Anthuriu m\%20schlechtendalii\%20hom epage.html Diakses pada 10 Agustus 2012

Lucas S (2008) Anthurium plowmanii Croat. http://www.exoticrain forest.com/ Anthurium\%20 plowmanii \%20pc.html Diakses pada 10 Mei 2012

Lucas S (2009) Anthurium cubense Croat. http://www.exoticrain forest.com/Anthurium\%20cub ense\%20pc.html Diakses pada 9 Agustus 2012

Mattjik NA (2010) Budidaya bunga potong dan tanaman hias. IPB Press. Bogor

Pulungan SI, Wiendi NMA (2010) Induksi keragaman genetik tanaman Anthurium wave of love (Anthurium plowmanii Croat) dengan radiasi sinar gamma dari ${ }^{60} \mathrm{Co}$ secara in vitro. Departemen Agronomi dan Hortikultura Fakultas Pertanian IPB. Bogor

Ratnasingham S, Hebert PDN (2007) BOLD: The barcode of life data system. Molecular Ecology Notes 7: 355-364

Stoeckle MY, Gamble CC, Kirpekar R, Young G, Ahmed S, Little DP (2011) Commercial teas highlight plant DNA barcode identification successes and obstacles. Sci Rep 1(42): 1-7

Xue CY, Li DZ (2011) Use of DNA barcode sensu lato to identify traditional Tibetan medicinal plant Gentianopsis paludosa (Gentianaceae). J Sys Evol 49 (3): 267-270 